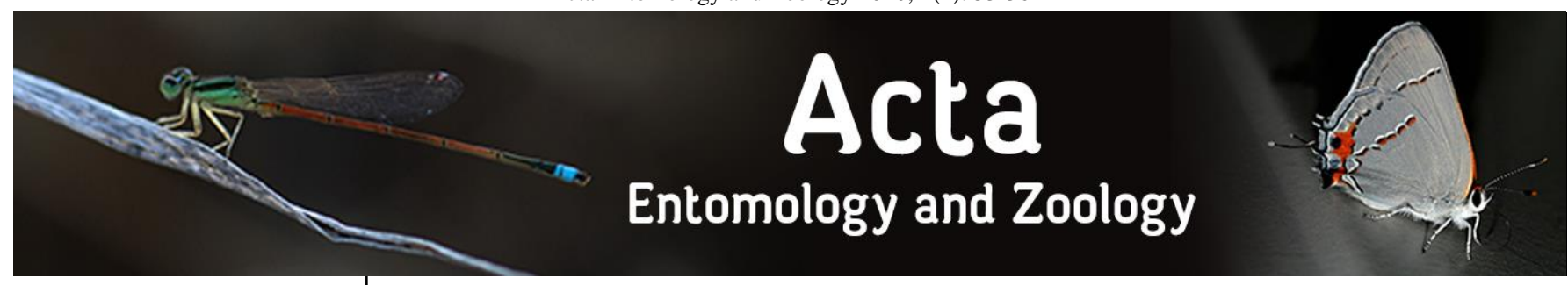

E-ISSN: 2708-0021 P-ISSN: 2708-0013 www.actajournal.com AEZ 2020; 1(2): 33-36 Received: 16-05-2020 Accepted: 20-06-2020

Sevidzem Silas L

a. Laboratoire d'Ecologie Vectorielle (LEV), Institut de Recherche en Ecologie Tropicale (IRET), Centre National de la Recherche Scientifique et Technologique, Libreville, Gabon, BP 13354 , Libreville, Gabon

b. Ecole Doctorale des Grandes Ecole (EDGE), Libreville, Gabon

Kong Anita B

Laboratoire d'Ecologie Vectorielle (LEV), Institut de Recherche en Ecologie Tropicale (IRET), Centre National de la Recherche Scientifique et Technologique, Libreville, Gabon, BP 13354, Libreville, Gabon

Koumba Armel A

Laboratoire d'Ecologie Vectorielle (LEV), Institut de Recherche en Ecologie Tropicale (IRET), Centre National de la Recherche Scientifique et Technologique, Libreville, Gabon, BP 13354, Libreville, Gabon

Zinga Koumba C

Laboratoire d'Ecologie Vectorielle (LEV), Institut de Recherche en Ecologie Tropicale (IRET), Centre National de la Recherche Scientifique et Technologique, Libreville, Gabon, BP 13354, Libreville, Gabon

Mintsa-Nguema R

Laboratoire d'Ecologie Vectorielle (LEV), Institut de Recherche en Ecologie Tropicale (IRET), Centre National de la Recherche Scientifique et Technologique, Libreville, Gabon, BP 13354, Libreville, Gabon

F Mavoungou Jacques

Laboratoire d'Ecologie Vectorielle (LEV), Institut de Recherche en Ecologie Tropicale (IRET), Centre National de la Recherche Scientifique et Technologique, Libreville, Gabon, BP 13354, Libreville, Gabon

Corresponding Author:

Sevidzem Silas I

a. Laboratoire d'Ecologie Vectorielle (LEV), Institut de Recherche en Ecologie Tropicale (IRET), Centre National de la Recherche Scientifique et

Technologique, Libreville, Gabon, BP 13354, Libreville, Gabon

b. Ecole Doctorale des Grandes Ecoles (EDGE), Libreville, Gabon

E-mail: sevidzem.lendze@gmail.com

\section{Molecular identification of Stomoxys and musca (Diptera: Muscidae) of veterinary importance in the pasture area of Ngaoundere}

\author{
Sevidzem Silas L, Kong Anita B, Koumba Armel A, Zinga Koumba C, \\ Mintsa-Nguema $\mathbf{R}$ and $\mathbf{F}$ Mavoungou Jacques
}

DOI: $\underline{\text { https://doi.org/10.33545/27080013.2020.v1.i2a.16 }}$

\begin{abstract}
Pasture flies are abundant pests in rangelands of Ngaoundere and information on their species composition is weak. For this reason a cross sectional entomological prospection using a Vavoua trap was conducted in the rainy season (September 2017) in Ngaoundere. Of a total of 568 Stomoxys (biting muscid) trapped, two species were identified $196 \mathrm{~S}$. niger niger $(34.51 \%, 9.33 \mathrm{Snn} / \mathrm{t} / \mathrm{d})$ and $101 \mathrm{~S}$. omega $(17.78 \%, 4.80 \mathrm{so} / \mathrm{t} / \mathrm{d})$ as well as 271 non-biting Musca spp $(47.71 \%, 12.90 \mathrm{~m} /$ vavoua and day). Molecular genotyping confirmed the morphological identification of Stomoxys species $(S . n$. niger and S. omega) and Musca species nucleotide sequences generated were $88 \%$ identical to Musca autumnalis.
\end{abstract}

Keywords: Stomoxyini, muscini, vavoua, PCR

\section{Introduction}

Muscids constitutes an important group of dipterous flies belonging to the family Muscidae. Individuals of the genus Stomoxys possesses biting mouthparts that permits them to suck blood from their hosts ${ }^{[1,2]}$. An important life trait of Stomoxys is that both male and female are blood sucking ${ }^{[1,2,3]}$. Individuals of the genus Musca possesses the spongy mouth part that permits them to lick blood and body fluids from hosts and other surfaces [4, 5]. Morphologically, the size of stable fly (Stomoxys) is about the same as the housefly, measuring from 4 to $7 \mathrm{~mm}$. Both individuals of the genera Stomoxys and Musca breed in dung, rotten vegetation materials plus faeces and urine ${ }^{[2,6]}$. Stomoxys are well known mechanical vectors of dangerous diseases (protozoans, helminthes, bacteria, and viruses) ${ }^{[3]}$. Mechanical transmission by this group is possible based on the fact that they are interrupted during blood feeding by their host and can rapidly switch to another calm counterpart to continue the processing hence leading to disease transmission ${ }^{[3,7]}$. Also, the fact that nonbiting muscids feed on open sores and secretions, indicates that they could be involved in contaminative transmission of highly contagious diseases ${ }^{[8]}$. Apart from Musca domestica that is common around human dwellings, Musca autumnalis (face fly) is frequently encountered around cattle and feed on body secretions. Musca autumnalis is known for mechanically transmitting several diseases such as bovine keratoconjunctivitis, infectious bovine rhinotracheitis, etc. ${ }^{[9,10]}$. Apart for the fact that individuals of both Stomoxys and Musca taxa are involved in disease transmission, they also cause direct effects to their hosts such as painful bites that stresses hosts, annoyance, decrease animal feeding time resulting in poor body condition and reduced traction power.

Based on geographical distribution of muscids, the face fly is native to Europe, Russia, China, North Africa, Korea, Japan, and Iran ${ }^{[11]}$. But Stomoxys are found in all several parts of the world ${ }^{[1]}$.

Morphologically, it is difficult for an untrained eye to separate individuals of the Stomoxys group from those of the Musca group. The identification of muscids of Cameroon have been made using morphological keys, with many unidentified species signaled. To effectively control pasture flies, a sensitive identification tool such as the Polymerase Chain Reaction (PCR) is required to confirm the morphologically typed individuals to be sure of what to target. For this reason we designed a study to identify muscids from Ngaoundere using PCR. 


\section{Materials and Methods \\ Description of study area}

The study area is located in Mbidjoro in Ngaoundere II, Vina Division of the Adamawa Region. It is about $15 \mathrm{Km}$ away from the town of Ngaoundere along the Ngaoundere/Tignere motorable highway. Geographically, the study herd is situated between Latitude $07^{\circ} 21^{\prime} 452^{\prime \prime} \mathrm{N}$ and Longitude $13^{\circ} 32^{\prime} 366^{\prime \prime} \mathrm{E}$ with an average altitude of $1523 \mathrm{~m}$ a.s.l. The study site is a pasture area with Goudali as the most dorminant cattle breed and others like red Fulani, white Fulani, Charlorais and their crosses (metis) are also common. The climate of this area is a typical Soudanosahelian type with vegetation consisting of savanna grasses grazed upon by cattle. The mean annual temperature is $23.1^{\circ} \mathrm{C}$, mean annual humidity is $63.2 \%$, mean annual rainfall is $1176.9 \mathrm{~mm}$ (rainy season) and wind usually blowing in the South East (SE) direction. Ecologically, the area consists of gallery forest, primary forest, secondary forest and open grass savanna.

\section{Fly collection}

Stomoxys spp. were trapped beside a herd around the Ngaoundere. Capture was made using a Vavoua trap ${ }^{[12]}$. Total trap exposition period was 5hours from 6:00 am to 6:00 pm. The Vavoua trap cages were emptied every evening $(6: 00 \mathrm{pm})$. This study was conducted in September 2017 for eight consecutive trapping days.

\section{Morphological fly identification}

The captured flies from both methods were first identified at species level using the taxonomic keys of Zumpt et al., ${ }^{[1]}$. Musca species were morphologically typed using the key of Gregory ${ }^{[13]}$ and Grzywacz et al., ${ }^{[14]}$.

DNA extraction, amplification and sequencing using fly samples

An aliquot $(100 \mu \mathrm{l})$ of the genomic DNA obtained using the Wizard ${ }^{\circledR}$ Genomic DNA purification kit (Promega ${ }^{\mathrm{TM}}$ ) following manufactures instructions was used for the molecular confirmation of our morphologically typed species (S. n. niger, $S$. omega) and Musca sp. Morphologically identified samples were used for the PCR amplification where primer sequence for the mtDNA used was defined according to Sharpe et al., ${ }^{[15]}$ : ITS2A (forward) (TGTGAACTGCAGGACACAT) and ITSB (reverse) (TATGCTTAAATTCAGGGGGT). It was performed in 25 $\mu \mathrm{l}$ reaction volume consisting of $0.6 \mu \mathrm{l}$ of each primer, $5 \mu \mathrm{l}$ 5xbuffer green, $2.5 \mu \mathrm{l} \mathrm{MgCl}_{2}, 1 \mu \mathrm{l}$ dinucleotide Tri Phosphates (dNTPs), $0.3 \mu \mathrm{l} \mathrm{Taq} \mathrm{polymerase} \mathrm{(Promega}{ }^{\mathrm{TM}}$, Madison, WI USA), $13 \mu \mathrm{l}$ RNase-free water and $2 \mu \mathrm{l}$ genomic DNA out of $100 \mu \mathrm{l}$. The reaction mixture was pipetted each into $0.2 \mathrm{ml}$ eppendorf tubes and placed in a Master cycler (Eppendorf®) with the following thermal cycling conditions: initial denaturation at $94^{\circ} \mathrm{C}$ for $4 \mathrm{mins}$, final denaturation step- $94{ }^{\circ} \mathrm{C}$ for 40 s, annealing $\left(55^{\circ} \mathrm{C}\right.$ for $30 \mathrm{~s})$, elongation $\left(72^{\circ} \mathrm{C}, 1 \mathrm{~min}\right.$ for 35 cycles and final extension at $72^{\circ} \mathrm{C}$ for 4 mins. Products were visualized in Midori green-stained $1.5 \%$ agarose gel with an expected product size of approx. 480bp ${ }^{[15]}$. Amplicons were prepared for sequencing following the EZ-Seq User guide briefly, 5 $\mu \mathrm{l}$ template and $5 \mu \mathrm{l}$ primer in each tube $(1.5 \mathrm{ml}$ eppendorf tubes)/well. Sanger sequencing was carried out at Macrogen. Sequences were aligned using Geneious version 10.2.3 and Evolutionary analyses were conducted in MEGA7.

Trap Apparent Density (ADT) defined as muscids caught per trap per day $(\mathrm{s} / \mathrm{t} / \mathrm{d})$ and mathematically expressed as

Trap Apparent Density $($ ADT $)=\frac{\text { Number of muscids captured }}{\text { number of traps } \times \text { number of trapping days }}$

\section{Results}

A total of 568 Stomoxys were caught and $S . n$. niger and $S$. omega were the only species morphologically identified. The non-biting Musca sp. was also identified morphologically. S. $n$. niger was the most abundant biting muscid in the collection (Table 1).

Table 1: The abundance of Muscids identified in the study area

\begin{tabular}{|c|c|c|c|}
\hline Muscidae & Number & \% & ADT \\
\hline Stomoxys species (biting) & & & \\
\hline Stomoxys niger niger & 196 & 34.51 & 9.33 \\
\hline Stomoxys omega & 101 & 17.78 & 4.80 \\
\hline Musca species (non-biting) & & & \\
\hline Musca autumnalis & 271 & 47.71 & 12.90 \\
\hline
\end{tabular}

ADT: Apparent density (number of flies caught per Vavoua trap per day)

The PCR products of the nine samples gave a positive signal with amplicons band size of 400bp which was the expected product size (Figure 1).

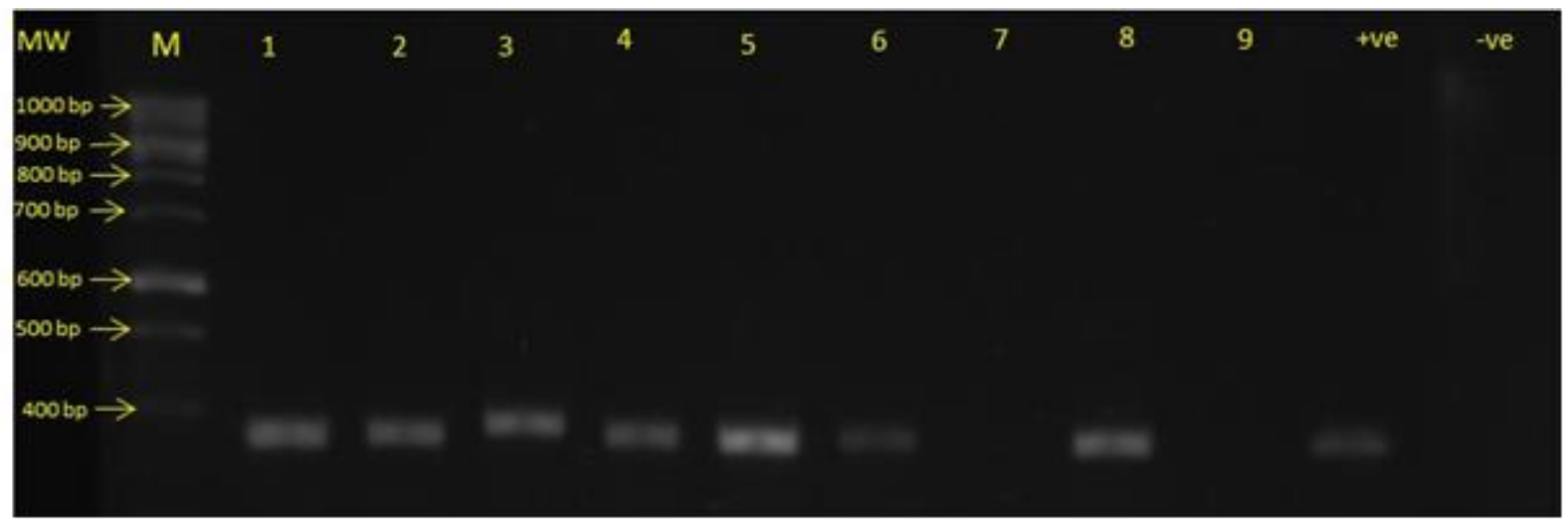

Fig 1: Gel electrophoresis of the amplicons of some muscids collected during the survey. 1 to 9 represent test samples, M: 100bp gene ladder, MW: molecular weight, +ve: positive control (S. n. niger), -ve: negative control. 
The sequencing results resulted in nucleotide sequences from two groups namely Musca and Stomoxys groups. From the blast into the already existing nucleotide sequences in the Gene Bank, our sequence code-S51_SN (Morphological identified as Musca sp.) was identical to Musca autumnalis, S49_SN and S53_SN (morphologically identified as S. omega) were identical to Stomoxys omega Sog7 and S50_SN (morphologically confirmed as Stomoxys niger niger) was identical to Stomoxys niger niger Snng2. A phylogenetic tree was constructed using sequences from the present study and reference sequences from the gene bank (Figure 2).

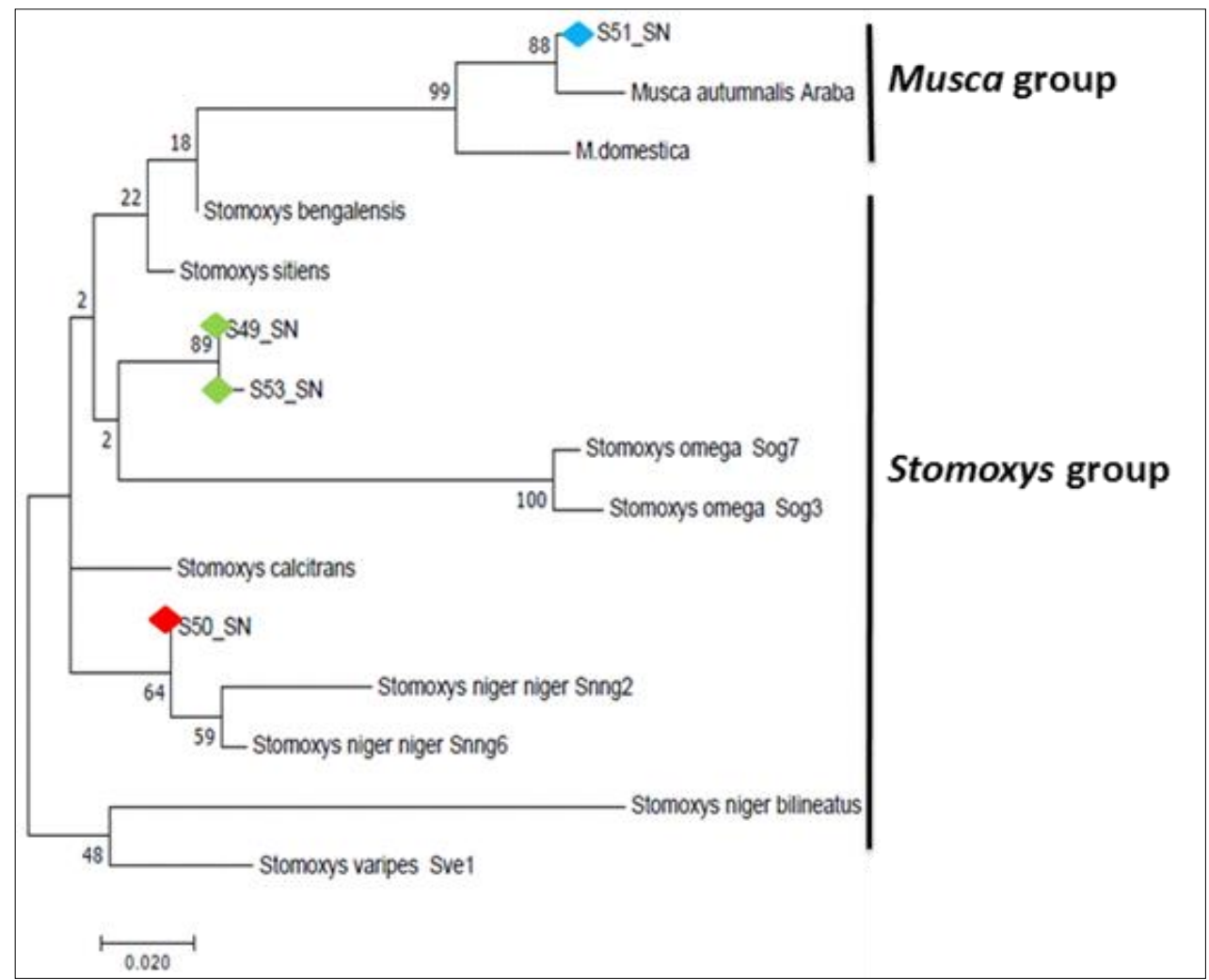

Fig 2: Molecular Phylogenetic analysis by Maximum Likelihood method showing the classification of Muscidae from the study.

The evolutionary history was inferred by using the Maximum Likelihood method based on the Tamura-Nei model ${ }^{[16]}$. The tree with the highest log likelihood is shown. The percentage of trees in which the associated taxa clustered together is shown next to the branches. Initial tree(s) for the heuristic search were obtained automatically by applying Neighbor-Join and BioNJ algorithms to a matrix of pairwise distances estimated using the Maximum Composite Likelihood (MCL) approach, and then selecting the topology with superior log likelihood value. The tree is drawn to scale, with branch lengths measured in the number of substitutions per site. All positions containing gaps and missing data were eliminated. Evolutionary analyses were conducted in MEGA7 ${ }^{[17]}$.

\section{Discussion}

The two species of biting muscids ( $S$. n. niger and S. omega) identified in the pasture area of Ngaoundere was not suprising as these species have already been presented in the report of Mamoudou et al.., ${ }^{[18]}$ in east, Sevidzem et al., ${ }^{[19,20]}$ in Ngaoundere, Sevidzem et al., ${ }^{[21]}$ in North and Hiol et al., [22] in the Littoral region of Cameroon. Based on the abudance of the different species of muscids collected, $S . n$. niger recorded the highest frequency. Stomoxys niger niger has been reported to develop and survive well in tropical African climates ${ }^{[1]}$. Stomoxys omega has been reported to be abundant in the rainforest of central Africa ${ }^{[22,23]}$. The present study revealed for the first time the presence of Musca autumnalis in Ngaoundere. Literature on the distribution of M. autumnalis shows that it is present in Northern parts of Africa ${ }^{[10]}$. The occurrence of this species in Cameroon (central African) could be due to the recent complex movement of trade and transhumance cattle in Africa hence moving along with this fly. Additionally, $M$. autumnalis was the most abundant species in our collection and this could be due to its ability to survive and breed in the study site as well as presence of cattle host for this species. The study of Sevidzem et al., [21] in North Cameroon indicated that Stomoxys and Musca genera shared same biotope and that the Musca group was more abundant. Apart of the fact that individuals of Stomoxys and Musca genera are involed in the mechanical transmission of dangerous diseases ${ }^{[3,9]}$, their importance in forensic entomology has been documented ${ }^{[14]}$.

\section{Conclusion}

The presence of two biting muscids $S$. $n$. niger and $S$. omega and one non-biting muscid Musca autumnalis in the rangeland of Ngaoundere were confirmed through molecular techniques. M. autumnalis is seen for the first time and was most abundant in the present collection.

\section{Acknowledgements}

Authors thank the BWS Stipendium scholarship for supporting part of this study.

\section{Conflict of interest}

Authors declare no conflict of interest. 


\section{References}

1. Zumpt F. The Stomoxyine biting flies of the world. Diptera: Muscidae. Taxonomy, biology, economic importance and control measures. Stuttgart: Gustav Fischer Verlag, 1973, 175.

2. Patra G, Behera P, Das SK, Saikia B, Ghosh S, Papia B et al. Stomoxys calcitrans and its importance in livestock: a review. International Journal of Advances in Agricultural Research. 2018; 6:30-37.

3. Baldacchino F, Muenvorn V, Desquesnes M, Desoli F, Charoenviriyaphap T, Duvallet G. Transmission of pathogens by Stomoxys flies (Diptera, Muscidae): a review. Parasite. 2013; 20:26.

4. Cortinas R, Jones CJ. Ectoparasites of cattle and small ruminants. Veterinary Clinic of North America Food and Animal Practice. 2006; 22:673-693.

5. Choudhary S, Kumar R, Choudhary Y, Kamboj M, Kumar A, Kumar S, Paul A. Flies Menaces in Dairy Farm and its Strategies for Prevention and Control- An Overview. International Journal of Livestock Research. 2019; 9:1-16.

6. Mavoungou JF, Nguema RM, Acapovi GL, Koumba RZ, Mounioko F, Sevidzem SL et al. Breeding Sites of Stomoxys spp. (Diptera: Muscidae), a Preliminary Study in the Makokou Region (North-East-Gabon). Vector Biology Journal. 2017; 2:1.

7. Lendzele SS, Eisenbarth A, Zinga-Koumba RC, Mavoungou JF, Renz A. Aspects of the bionomics of hematophagous symbovine dipterans in a hyperinfested rangeland of Ngaoundere (AdamawaCameroon). Journal of Asia-Pacific Entomology. 2019; 22:1019-1030.

8. Sevidzem SL, Mamoudou A, Dickmu S, Renz A, Acapovi-Yao GL, Mavoungou JF et al. Risk Factors for the Contamination of Wild Stomoxys niger niger Macquart 1851 (Diptera: Muscidae) with the Foot-andMouth Disease Virus. Current Research in Agricultural Sciences. 2019a; 6:95-108.

9. Gerhardt RR, Allen JW, Wallace HG, Smith PC. The role of face flies in an episode of infectious bovine keratoconjunctivitis. Journal of the American Veterinary Medicine Association. 1982; 180:156-59.

10. Krafsur ES, Moon RD. Bionomics of the Face Fly, Musca autumnalis. Annual Review of Entomology. 1997; 42:503-23.

11. Pcikens LG, Miller RW. Biology and Control of the Face Fly, Musca Autumnalis (Diptera: Muscidae). Journal of Medical Entomology. 1980; 17:195-210.

12. Laveissière $C$, Grébaut $P$. Recherche sur les pièges à glossines (Diptera: Glossinidae). Mise au point d'un modèle économique: le piège «Vavoua». Tropical Medicine and Parasitology. 1990; 41:185-192.

13. Gregor F, Rozkošný $R$, Barták $M$, Vaňhara J. The Muscidae (Diptera) of central Europe. Folia Fac Sci Nat Univ Masaryk Brun Biology. 2002; 107:1-280.

14. Grzywacz A, Hall MJR, Pape T, Szpila K. Muscidae (Diptera) of forensic importance-an identification key to third instar larvae of the western Palaearctic region and a catalogue of the muscid carrion community. Integrated Journal of Legal Medicine. 2017; 131:855866.

15. Sharpe RG, Harbach RE, Butlin RK. Molecular variation and phylogeny of members of the Minimus group of Anopheles subgenus Cellia (Diptera: Culicidae). Systematic Entomology. 2000; 25:263-272.

16. Tamura K, Nei M. Estimation of the number of nucleotide substitutions in the control region of mitochondrial DNA in humans and chimpanzees. Molecular Biology and Evolution. 1993; 10:512-26.

17. Kumar S, Stecher G, Tamura K. MEGA7: Molecular Evolutionary Genetics Analysis Version 7.0 for Bigger Datasets. Molecular Biology and Evolution. 2016; 33:1870-4.

18. Mamoudou A, Ikoum D, Sevidzem SL, Njan-Nloga AM, Sieumeni DA, Mohammadou B et al. Bovine trypanosomiasis and vectors in Lom and Djerem Division of East-Cameroon. African Journal of Biological Sciences. 2020; 2:20-29.

19. Sevidzem SL, Mavoungou JF, Zinga-Koumba CR, Koumba AA, Duvallet G. Factors Influencing Seasonal and Daily Dynamics of the Genus Stomoxys Geoffroy, 1762 (Diptera: Muscidae), in the Adamawa Plateau, Cameroon. International Journal of Zoology. 2019b; 3636943:9.

20. Sevidzem SL, Tchawe R, Zinga-Koumba R, Mamoudou A, Ndjonka D, Mavoungou JF. Insecticide coated screen models reduce insect-vector population in a pasture area in Ngaoundere, Cameroon. Trends Applied Science and Research. 2019c; 14:80-89.

21. Sevidzem SL, Mamoudou A, Acapovi YGL, Achiri M, Tchuinkam T, Zinga KCR et al. First Inventory of Nonbiting and Biting Muscids of North Cameroon. International Research Journal of Biological Sciences. 2016; 5:12-20.

22. Hiol V, Sieumeni AD, Mamoudou A, Sevidzem SL, Njan-Nloga AM, Nukenine EN. Spatio-Temporal Dynamics of Glossinidae, Tabanidae and Stomoxyidae around the Douala-Edea Wildlife Reserve in Cameroon. American Journal of Entomology. 2019; 3:36-42.

23. Sevidzem SL, Affiri OJM, Zinga-Koumba CR, Mounioko F, Koumba AA, Nguema RM et al. Abundance and Diurnal Activity Rhythm of Stomoxys spp. in a Wildlife-human Interface in Makokou (North East-Gabon). Asian Journal of Research in Zoology. 2019d; 2:1-10. 